\title{
SER VIVO: LA LITERATURA EN LA GUERRA (SOBRE LOS PICHICIEGOS DE RODOLFO FOGWILL)
}

\author{
BEING ALIVE: LITERATURE IN WAR \\ (ABOUT LOS PICHICIEGOS BY RODOLFO FOGWILL)
}

Fermín A. RODRÍGUEZ

Conicet-UBA

\begin{abstract}
Resumen: Sobre fines del milenio, según una configuración cultural dominada por la temporalidad de la crisis y el vaciamiento general del sentido de lo nacional, distintos procesos políticos, estéticos y culturales en América Latina pusieron en el centro de la reflexión nuevas formas de subjetividad y modos de vida surgidos más allá de las formas tradicionales de identificación imaginaria del individuo con la nación. En tanto pone en juego nuevos modos de organización de lo sensible, Los pichiciegos de Rodolfo Fogwill (1983) constituye un corte respecto de las territorializaciones tradicionales del Estado. La novela de Fogwill es una picaresca de desertores de la Guerra de Malvinas abandonados en el campo de la excepción que, en más de un sentido, predice el cinismo de las políticas neoliberales y las nuevas formas de asociación de cuerpos sustraídos a las identificaciones nacionales de la Argentina de la década del 90.
\end{abstract}

Palabras clave: literatura y guerra - neoliberalismo - biopolítica - Fogwill - comunidad

Abstract: In the final decades of twentieth century new subjectivities and life forms surfacing beyond the traditional ways of imaginary identification of the individual with the nation have became the core of different political, aesthetic and cultural processes in Latin America, according to a cultural configuration dominated by the temporality of the crisis and the emptying of the meaning of the national. By introducing new ways of organization of the sensible, Rodolfo Fogwill's novel Los pichiciegos (1983) represents a rupture with the traditional territorialization of the State. Fogwill's novel is a picaresque of deserters from the Guerra de Malvinas abandoned in a state of the exception that predicts in many ways the cynicism of neoliberal policies as well as new forms of community in Argentina during the 90's.

Key Words: literature and war - neoliberalism -- biopolitics - community - Fogwill 
$\mathrm{E}$ n su rol de articuladora de comunidades nacionales, la literatura latinoamericana del siglo diecinueve fue uno de los mecanismos fundamentales de naturalización del estado-nación. Lo nacional, como operación civilizatoria, está en la base de una serie de textos que distribuyen cuerpos y sentidos adentro y afuera del mapa de lo social, separando del plano de lo que una comunidad reconoce como persona eso que, en su superabudancia vital, vive de perder la forma: el cuerpo ingobernable de la barbarie-multitud, desestabilizando pactos y límites.

La periodización puede variar, pero en términos generales, podría decirse que un siglo más tarde, desde finales del siglo XX, esa matriz nacional, que fue la condición de tantas definiciones de las culturas latinoamericanas, comienza a resquebrajarse. La literatura deja de ser la expresión de una identidad nacional, con escritores dedicados a vaciar de sentido el reparto de espacios y de cuerpos que desde los años de formación de las culturas latinoamericanas definieron el territorio de lo que reconocemos y leemos como literaturas nacionales. La grieta entre personas y seres vivos se ensancha en una cultura que ensaya con otros saberes y sensibilidades del cuerpo y sus poderes, con otros espacios y tiempos alternativos al orden nacional.

Nuevos tipos de espacializaciones no organizadas en torno a la constitución nacional del territorio, poblados por sujetos básicamente económicos, se multiplican por una ficción que dejó detrás suyo un tendal de cuerpos precarizados y abandonados por las formas tradicionales de identificación con el estado-nación. De los espacios-territorio, estabilizados dentro de límites por operaciones de producción y reproducción de ciudadanía y autoridad, pasamos a espacios de exclusión cargados de vida, espacios-población (Cavalletti 151) pre-personales y fluidos, codificados y regulados por un entramado de poderes y controles que ya no tienen al estado ni a las formas de habitar la nación como referencia exclusiva para la producción y regulación de la subjetividad.

La producción de espacios desestatizados se multiplica por ficciones de vida que, en el reverso de las retóricas nacionales, recogieron entre sus páginas la realidad somática de sujetos reducidos a su ser viviente. Rodolfo Fogwill en la Argentina, Diamela Eltit en Chile, Joāo Gilberto Noll en Brasil o Mario Bellatin en México, entre otros, trabajan con un nuevo régimen de significación donde lo más importante parece ser lo biológico, lo viviente, la materialidad de lo corporal como objeto de tecnologías de control que hacen de la precarización una estructura permanente de la existencia.

I. A la vanguardia de este proceso de debilitamiento y desintegración de las identificaciones nacionales hay una novela escrita en Buenos Aires que, en una coyuntura saturada de entonaciones épicas y apelaciones a la patria, anticipó el "sálvese quien pueda" de las "democracias de mercado" de los años 90, que hoy vuelven a recrudecer a lo largo de todo el Cono Sur. Se trata de Los pichiciegos, la novela que Rodolfo Fogwill (1941-2010) escribió a mediados de junio de 1982 en plena guerra entre 
Argentina y Gran Bretaña por la soberanía de las Islas Malvinas. En clave de picaresca, narra la historia de un grupo de desertores que, en plena batalla, abandonaron el ejército para montar en el campo de la excepción un tenaz dispositivo de supervivencia que les permitiera salir vivos de las islas. Novela "visionaria", subtitulada Visiones de una batalla subterránea, Los pichiciegos se adelantó a su tiempo no sólo al prever lo que sería el retorno de la democracia después de seis años de una violenta dictadura militar, sino también, como virtualidad, el cinismo de las políticas neoliberales y las nuevas formas de asociación de cuerpos sustraídos a las identificaciones nacionales de la Argentina de la década del 90.

Dice la leyenda que el propio Fogwill se encargó de difundir que la novela fue escrita en menos de una semana, en un lapso que, según las diferentes versiones, va de dos a siete días, sin la más mínima distancia temporal de un conflicto que se desarrolló entre el 2 de abril, día del desembarco argentino en las islas, y el 14 de junio de 1982, fecha de la rendición, y que precipitó el fin de la dictadura cívico-militar que gobernaba el país desde el golpe de estado del año 1976. La novela fue publicada en 1983, pero según se registra en la última página de la primera edición, Fogwill, con los ingleses pisándole los talones, habría terminado de redactar el manuscrito el 17 de junio, apenas tres días después del final de la guerra.

¿Qué se jugaba en esa precipitación de la palabra literaria por adelantarse a los acontecimientos históricos? En un principio, como deduce Gamerro ${ }^{1}$, anticiparse a las noticias y a su lógica de la manipulación y tergiversación del sentido, que no dejaban ver aquello que Fogwill, indiferente al fervor patriótico de las mayorías, se veía venir. La guerra no podía durar, los signos indefinidos que anunciaban la derrota estaban en el aire. Sin tiempo ni lugar "donde buscar palabras mejores que explicaran las cosas" (86), como consta en la propia novela, Fogwill prevé un final anunciado, pero a diferencia de los pichiciegos más despiertos, que sabían que la guerra terminaba aunque "no sabían cómo" (112), montó con el lenguaje mudo de las cosas y el lenguaje cifrado de las imágenes una máquina de comprensión compleja que, trabajando en el umbral entre la razón de los hechos y las ficciones, rompió con el régimen de evidencia sensible que dominaba la ficción urdida por la Junta Militar y sus medios adeptos.

Así, la cuestión de la guerra en la literatura--el problema de su representación en la novelaqueda desplazada por el problema de una literatura que en la guerra se enfrentó con la información oficial y el modelo de experiencia empobrecida por la cadena de consignas que desde los medios cómplices del poder repetía, con tonos épicos, que estábamos ganando. ("Estamos ganando", mentía la revista Gente el 6 de mayo de 1982 o “iSeguimos ganando!”, el 29 de mayo, desde tapas que están en la memoria afectiva de los argentinos.) ${ }^{2}$ ¿A quién está refutando la primera línea de la novela, que comienza con la frase "Que no era así", si no es a los medios y a sus representaciones falsas (7)?

\footnotetext{
${ }^{1}$ Carlos Gamerro repasa a lo largo de distintas entrevistas la leyenda de la cantidad de días que le llevó a Fogwill escribir Los pichiciegos, contando los días (y los gramos de cocaína) que le llevó completar el manuscrito. "Confieso que la polémica no me quita el sueño", aclara el autor de Las islas, pero observa que la insistencia en la velocidad de la escritura es un índice de que Fogwill "tenía que terminarla antes de que terminara la guerra” (Gamerro 444).

${ }^{2}$ Para Vezzetti, la lucha por la información y por la verdad en el campo de la memoria y el testimonio fue un plano decisivo del enfrentamiento con la dictadura y su control estricto sobre la información pública (Vezzetti 21).
} 
Quique, el pichiciego que vivió para contarla, está hablando de la nieve, a la que imaginaba "blanca, liviana, bajando en línea recta hacia el suelo...y tiene trineos con campanillas". Pero sólo "en el televisor la nieve es blanca" y cubre todo, y no se hunde ni se hace barro ni atraviesa la ropa. Porque allí "afuera", que es el frío y el viento de la intemperie, pero también el afuera de la realidad de los medios, ${ }^{3}$ la nieve era "amarilla, como crema... pegajosa, pastosa. Se pega por la ropa, cruza la boca de los gabanes, pasa los borceguís, pringa las medias" (6-7). Y era a ese "barro pesado, helado, frío y pegajoso" (6) lo que los medios llamaban nieve.

Había que defenderse de la manipulación de la información y del poder de hacer creer de los medios, reconfigurando la experiencia sensible a partir de un sensorio diferente al de la dominación ${ }^{4}$. Otra distribución de lo sensible, otro mapa de las islas era posible, hecho a escala del cuerpo y sus saberes según las formas de visibilidad y de inteligibilidad de una novela en más de un sentido "visionaria".

Porque la guerra de Los pichiciegos fue, en palabras del propio Fogwill en ocasión de la reedición en 2006, un "experimento mental" de alguien que escribe sobre la experiencia sin haberla tenido, poniendo en variación una serie de saberes del cuerpo y los poderes que lo moldean, para construir con ellos, por extrapolación, un espacio donde la verdad tiene la forma de una visión -esas Visiones de una batalla subterránea a las que hace referencia el subtítulo.

¿Qué es Los pichiciegos sino una fábrica de producir visiones y enunciados, una máquina omnívora de múltiples entradas capaz de aspirarlo y procesarlo todo -discursos sociales, contra relatos, fragmentos de prensa extranjera, jergas técnicas, catálogos de armas, dialectos regionales, saberes sensibles, protocolos de experiencia? "Me dije" - recuerda Fogwill en una entrevista de Martín Kohan--“'Sé de...' Yo sabía mucho del Mar del Sur y del frío, porque yo sufrí mucho del frío navegando. Sabía de pibes, porque veía a los pibes. Sabía del Ejército Argentino, porque eso lo sabe todo tipo que vivió la colimba"5. Y combinando toda esa información, construyó, a distancia de los hechos no menos que de la verosimilitud inventada de la novela, "un experimento ficcional que está mucho más cerca de la realidad que si me hubiera mandado a las islas con un grabador y una cámara de fotos en medio de la guerra" (Fogwill 2006). El escritor es un hombre-máquina, un hombreexperimental que no inventa nada que no exista como virtualidad, y en tanto "visionario", construye

\footnotetext{
${ }^{3}$ Acerca de vivir apartado de la realidad modelada por los medios, dice Fogwill a propósito de su novela Vivir afuera de 1998: "Vivir afuera es una novela casi te diría intimista", responde Fogwill. "Porque es eso. Ahora la leo y no veo ninguna doctrina, está escrita por un tipo que llevaba ya —y sí, bueno, ahora llevo más- quince años ausente de la realidad mediática; yo no mire televisión en quince años, no sé ni quiénes son los tipos estos que todo el mundo nombra. Entonces, si no tenés ese elemento, estás muy lejos de lo real público" (Kohan 2006). Sacando cuentas, los quince años de ausencia de la realidad mediática que declara Fogwill coinciden con el final de la guerra y el retorno de la democracia.

${ }^{4}$ Hay una política de la literatura y de la estética en general, dice Rancière en La malaise dans l'esthétique, que consiste en "suspender las coordenadas normales de la experiencia sensorial" (39) para producir o bien una forma sensible autónoma o bien configurar un espacio común y "democrático" a la manera de Los pichiciegos.

${ }^{5}$ Dice Pilar Calveiro, a propósito del servicio militar obligatorio (popularmente llamado "colimba") que debían cumplir los varones mayores de 18 años en la Argentina: "Cada soldado, cada cabo, cada oficial, en su proceso de asimilación y entrenamiento aprendió la prepotencia y la arbitrariedad del poder sobre su propio cuerpo y dentro del cuerpo colectivo de la institución armada" (11). Tuvo vigencia desde 1904 hasta 1994, cuando el presidente Carlos Menem decretó su final debido a la desaparición y muerte del conscripto Omar Carrasco, victima de torturas por parte de sus superiores, mientras prestaba servicios en el Ejército Argentino.
} 
con su imaginación alucinada una serie de escenas sensibles pobladas de personajes a los cuales les presta sentimientos, palabras y experiencias verdaderas.

En este sentido, corriendo entre líneas, hay otra "nieve" acumulándose sobre el blanco de la página, que provee la dosis de potencia afectiva necesaria para que la escritura no se detenga. La cantidad de cocaína que dice Fogwill haber consumido mientras redactaba el manuscrito, ¿no introduce una "química" de los afectos y las palabras en tensión con la reproducción mecánica de la palabra ajena? La novela "está escrita con doce gramos de cocaína en dos días y medio. La realidad no existía para mí"-recuerda Fogwill, colando en la economía de la escritura una carga afectiva concreta que hace aparecer la "inspiración", irónicamente, como un proceso material y sensible de "aspiración"6. La velocidad de la escritura corre en paralelo a la velocidad de las sinapsis inducidas por la droga, devenida fuente de la energía afectiva necesaria para crear las "visiones" que pueblan el relato de afectos incandescentes.

II. "Yo anotar no... a mí [me interesa] ¡saber!" (89)—se escucha decir al escritor de Los pichiciegos mientras registra en una cassette el recuerdo de Quique de sus días de enterrado vivo en las islas. El grabador del corresponsal de guerra, del que Fogwill desconfiaba porque "con la inmediatez de los hechos te perdés" (Fogwill 2006), aparece ahora en el futuro próximo en el que transcurre la novela, cuando la guerra y la dictadura ya terminaron y el escritor sin nombre, que ronda como personaje toda la obra de Fogwill, se reúne con un combatiente de Malvinas, ya reintegrado a la vida civil, para registrar su testimonio y escribir a partir de las cintas grabadas lo que terminará siendo Los pichiciegos. Se trata de una ficción de testimonio, hecha con nudos de realidad y materiales que están trabajados como si fueran verdaderos, donde lo ficticio es, antes que nada, la enunciación, la escena de transmisión oral de la experiencia que va insinuándose de a poco en una novela orientada hacia el relato documental y de no ficción.

¡Que la escritura corra más rápido que las noticias en vivo y en directo, que la velocidad de inscripción se adelante a la velocidad de transmisión de las consignas e imágenes oficiales! Pero, también, que la escritura se adelante al testimonio de los soldados, que a su regreso de las islas, comenzarían a hablar a partir del valor de verdad de un "yo" con el poder de recordar y transmitir la verdad de la experiencia ${ }^{7}$.

Pero al escritor - una figura ambigua: conoce de armas, tiene contactos en el Ministerio--no le interesa el empirismo etnográfico de una literatura que registre pasivamente la experiencia del testigo: no se trata de recordar ni de hacer recordar, ni de la reproducción mecánica de la palabra ajena, sino

\footnotetext{
${ }^{6}$ Droga y escritura (blanco sobre blanco) se encuentran en la escena de escritura de la novela: “¿Y eso qué es...? -preguntó. -Nada... un remedio para la sinusitis. - ¿Y así te lo ponés? -quiso saber? -Sí... porque es mejor, más directo -le dije y recomencé a escribir" (97).

${ }^{7}$ Gamerro también señala el temor de Fogwill de que la novela sea leída en serie con los testimonios: "El primer libro de testimonios de soldados de Malvinas, Los chicos de la guerra de Daniel Kon, se escribe a partir de entrevistas realizadas apenas terminada la guerra, entre junio y agosto; para cuando sale Los pichiciegos, en diciembre de 1983 ya lleva once ediciones" (Gamerro 445).
} 
de entender y reflexionar a partir del otro. ¿Por qué si no, mientras Quique habla y a pesar de que el grabador está siempre encendido, el escritor de Los pichiciegos no deja de tomar notas? "No es lo mismo lo grabado que lo escrito" (97)- explica el escritor en algún momento, cuando Quique lo deja solo para "redactar y pensar" (98), cruzando discursos y saberes, haciendo trabajar el lenguaje, sin que la inmediatez del testimonio del que tuvo la experiencia lo distraiga.

La posibilidad entonces de entender la guerra queda situada más allá de las mentiras de la ficción o del valor de verdad del testimonio: basta con desplegar un espacio de cálculos a partir de los saberes y la memoria del cuerpo y de las cosas que lo afectan; basta con sentir y pensar en común, por debajo de las diferencias culturales, incluso de las diferencias entre especies. Viendo bajar a los ingleses de los helicópteros, por ejemplo, los soldados argentinos entienden "lo que debió sentir aquella oveja que se iba yendo por el campo con tanto disimulo" (103), pensando, cuando hay soldados cerca, "este me garcha, me pela la lana o me degüella para comer" (101).

El problema de Los pichiciegos no era sólo entender la guerra y lo que estaba pasando por debajo de las noticias y los testimonios, sino usar la guerra para entender: como dice alguno de los personajes, la guerra, "te da tiempo, aprendés más, entendés más" (51). Entendés, gracias a ellas, lo potente y frágil que es la vida; entendés que el poder funciona directamente sobre los cuerpos y que para captarlo hay que reorganizar el mapa de lo sensible; entendés que para los de abajo la excepción es la regla y que la producción de un cuerpo biopolítico, afuera del campo de la ciudadanía, es el fundamento oculto de la dominación.

Porque en el vértigo de sus visiones, en su deseo de anticiparse a los hechos y a los testimonios, en la adicción de Fogwill a la escritura y su querer entender desde la literatura el funcionamiento de la estética que está en la base de la política (Rancière 2007), Los pichiciegos fue tan lejos que quedó por delante de su tiempo, en una tierra desconocida, mostrando, a partir de formas de hacer, decir y sentir en común, la emergencia de una economía de la vida y de la muerte que, por debajo del umbral de reconocimiento y legibilidad, ya estaba reorganizando, silenciosamente, las formas de configuración de lo público.

III. ¿Quiénes son los pichiciegos del título? Un grupo de veinticuatro soldados que en plena guerra de Malvinas le sacaron el cuerpo al ejército para enterrarse bajo tierra y montar con todo lo que tenían a mano un tenaz dispositivo de supervivencia que les permitiera salir con vida del conflicto. Hueco abierto en un territorio en disputa entre dos soberanías, el pozo en el que se hunden los pichis delimita el vacío que se abre en el espacio de la identidad nacional cuando un grupo de individuos que renunciaron al uniforme (y a lo uniforme de la identidad nacional) se autoconstituye como grupo-los pichis son multitud: se decía entre los soldados "que había como mil" (22)—y monta con recursos autogestivos una máquina comunitaria de producir lazos y conexiones que, más que sobrevivir, les permitió volver posible la vida. 
Hay una leyenda de la Primera Guerra Mundial, evocada por Zizek, sobre bandas de desertores habitando en una tierra de nadie entre las trincheras del frente. Estaban formadas por miembros de todos los ejércitos y naciones, que vivían en paz y amistad en una suerte de comunidad alternativa en contra de la guerra, ayudándose entre sí y evitando ser descubiertos. Como los pichis, vestían en harapos, con largas barbas, y sólo salían de noche, después de una batalla, a saquear cadáveres y conseguir comida y agua. Estas tribus de parias salvajes, dice Zizek, representan la negación de la guerra, "la división real, la única que importa", desde el momento que los vuelve enemigos de la guerra misma (Zizek 112-113).

La leyenda de la tribu de parias de Zizek no es exactamente la de los pichiciegos. A diferencia del refugio de los soldados europeos, la pichicera no es "una isla de paz entre las trincheras", donde reinaría, por debajo de las líneas del frente, "una fraternidad universal” (Zizek 113). Más bien, se trata de un dispositivo provisorio cargado de ambivalencia e indeterminación montado por un grupo de conscriptos argentinos que "se cortan solos" (22) para salir vivos de una guerra perdida, sin fervor patrio ni chances de hacerle frente a la profesionalidad, la crueldad calculada y la abrumadora superioridad técnica del ejército inglés - no menos que los abusos, las torturas y los enormes déficits de equipamiento y logística en materia de víveres, abrigo y armas de las fuerzas armadas argentinas. Los pichis no están necesariamente en contra de la violencia, ni desertan para ser libres en nombre de la amistad universal entre los hombres. Más bien, excavando por todos lados, tratan de encontrar una salida que de ninguna manera puede reducirse a un refugio alejado del mundo.

La leyenda que circulaba entre los soldados decía que los pichis "eran muertos que vivían debajo de la tierra, cosa que a fin de cuenta era medio verdad" (68), reconoce Quique como testigo, en una tradición que se remonta al fusilado que vive de Operación masacre de Rodolfo Walsh. Como los fusilamientos clandestinos documentados por Walsh — un hecho verdadero que en 1957 parecía una ficción--, las visiones de la guerra de Fogwill son cortes con la ficción del estado, experiencias límite que, como suele decirse, parecen mentira porque escapan del régimen de verosimilitud del aparato de propaganda mediático (donde la mentira parece verdad). ${ }^{8}$

Eso de que vivían debajo de la tierra era cierto, la parte verdadera de la leyenda; pero no lo de que estaban muertos. De hecho, son en más de un sentido los vivos de esta historia, sujetos a primera vista enterrados en su cuerpo biológico, con derecho a la vida y a la persistencia, tratando de sobrevivir afuera de la ley del ejército y de la ciudadanía en una comunidad sin Estado donde se debilitan las fronteras nacionales y sociales ${ }^{9}$ y se borra también la diferencia entre humanos y animales.

\footnotetext{
${ }^{8}$ Dice Ricardo Piglia en Las tres vanguardias, acerca de los materiales de la no ficción: “Operación masacre está construida sobre la base de la tensión entre el hecho de que lo imposible es verdadero -hay fusilados que viven-- y el hecho de que lo verdadero es inverosímil" (201). Es inverosímil que un muerto viva, no menos que una revolución "Libertadora", como se autodesignó la dictadura cívico-militar que derrocó en 1955 al gobierno democrático de Juan Domingo Perón, en nombre de las instituciones republicanas, se ponga afuera de la ley y asesine personas civiles en el campo de la excepción. ${ }^{9}$ La territorialización nacional se desintegra a favor de identificaciones culturales locales o regionales. Los argentinos eran antes que nada porteños, formoseños, bahienses, sanjuaninos, tucumanos, cordobeses (hasta un uruguayo había, al que “escribieron argentino" [11]). Igualmente, los ingleses no eran ingleses sino "escot, wels, gurjas" (56).
} 
El nombre que adoptan, con el cual crean líneas de desidentificación del rol de soldados, corresponde a un animalito subterráneo de la llanura, un pequeño armadillo o mulita de unos $10 \mathrm{~cm}$. de largo, que cabe en la palma de la mano. Vive debajo de la tierra, en cuevas hondas (" $i d e$ hasta mil metros!"- exagera un pichi [21]) que cavan a gran velocidad. Son bichos nocturnos, no ven, y tienen una armadura formada por placas que los vuelve, como la vida misma, duros y frágiles a la vez, porque si se enrollan como una bola, son casi inexpugnables, pero si llegan a darse vuelta no pueden enderezarse, dejando expuestas sus partes blandas, de un pálido color rosado, con pelos blancos en el vientre.

IV. Pero el pichiciego (Chlamyphorus truncatus) aguanta, repite la novela a modo de consigna. Ovillado sobre una forma de vida, los pichis aguantan en su querer vivir la aplicación de un poder que se ejerce sobre los cuerpos en forma directa e indirecta, asesinando según la lógica del derecho soberano de matar no menos que exponiendo a los soldados a una muerte lenta por abandono y pobreza que anticipa, según otra "visión”, las políticas neoliberales de los años 90. El poder sobre la vida escarba en sus partes blandas, para extraer de allí una instancia de control apropiable y gestionable: la vida separada de todo lazo, objeto del poder soberano; el mítico sustrato biológico de la nación con el que se hacen los individuos y constituyen las poblaciones ${ }^{10}$, punto de partida de la imaginación biopolítica que nutre de saberes y figuras toda la literatura de Fogwill, desde Vivir afuera y La experiencia sensible hasta su novela póstuma La introducción.

Los pichis aguantan organizándose colectivamente en torno a un querer vivir que le dé a las necesidades fisiológicas más elementales una configuración política y espacial. Con sus cavidades, huecos y túneles, la pichicera no es otra cosa que una intervención en la organización espacial del poder que desfonda los confinamientos estatales. Porque al espacio regular de la tropa, donde cada cuerpo debería contar como parte de un mecanismo disciplinario, los pichis le oponen el espaciopoblación de la pichicera, un pozo en expansión con algo de madriguera, mal ventilado y apuntalado por medio de durmientes, donde los individuos se mezclan en base a rasgos preindividuales y biológicos compartidos por todos en tanto seres vivientes: todos los que están ahí tienen un cuerpo con el poder de afectar y ser afectado, necesitado de otros cuerpos tanto como de asistencia técnica; todos exhiben, en su vulnerabilidad, lo que se necesita para sostenerse de pie y aguantar con vida: alimento, refugio, calor, protección, medicina, aire puro.

Por cierto, hablar de desertores--soldados conscriptos que desobedecen a sus superiores y abandonan las filas del ejército en nombre de una humanidad superior — no aclara demasiado las cosas. No se deserta de un ejército que impone la precariedad entre aquellos que recluta, donde los propios

\footnotetext{
${ }^{10}$ Dice Gabriel Giorgi, analizando la constitución de las naciones latinoamericanas en torno a un núcleo de pureza racial politizado y medicalizado, que desde una perspectiva biopolítica, un cuerpo "se define a partir de una separación respecto de sí mismo, y de la posibilidad de aislar en él eso que constituye el patrimonio colectivo de la población-o bien, lo que la amenaza. Es a partir de esa distinción que se hizo posible la biologización de razas, clases y grupos sociales, su jerarquización y gestión, justamente porque aísla y objetiva una dimensión que se vuelve la instancia de control, de gestión y de investidura política" (107).
} 
oficiales son los principales enemigos de conscriptos que apenas cuentan con unos pocos meses de instrucción, sin entrenamiento adecuado para combatir, mal pertrechados, con armas obsoletas, sin el abrigo adecuado ni comida caliente para soportar el frío, ni cuidado médico. No se deserta porque al abandonarlos a su suerte, el Estado argentino había renunciado previamente al contrato social que lo unía con el ciudadano-soldado, dispuesto a sacrificar la vida a cambio de inclusión, protección, seguridad social, empleo asegurado de por vida, pensión de guerra, etc.

En este sentido, mucho antes de enterrarse vivos en una cueva, los pichis ya habían sido dejados caer en uno de esos agujeros latinoamericanos de privaciones y violencia donde el estado "encierra afuera" de instituciones fallidas a cuerpos imprescindibles y prescindibles a la vez, sacrificables en aras de la nación. Imprescindibles para la defensa de la patria, los conscriptos, procedentes en su mayoría de las provincias más pobres del país, constituyen cuerpos devaluados, desechables, aniquilados en términos físicos y psíquicos por su propio ejército. ¿Cuántas noches habrán pasado los pichis a la intemperie quietos, "calaboceados" (26) por orden de algún oficial o suboficial, esto es, enterrados o estaqueados, con el frío y la nieve haciendo de celda? ${ }^{11}$

Son, en este sentido, los indigentes, los pobres de esta guerra, hacinados, envilecidos por el frío, con la piel sucia de hollín y cuarteada por la intemperie, la barba crecida, el pelo duro como cuero, los pómulos rojos, vestidos peor que pordioseros, sin forma humana reconocible. "Ni cara tenían" (91), se dice en la novela, y el hecho de verlos reducidos a mera población de cuerpos sin rostro "después de haber visto gente verdadera en la vida", era la prueba de que no pasarían el invierno (91). Su visión era insoportable para los británicos que, rubios, con la cara limpia y bien afeitada, los miran con lástima, frunciendo la nariz por el olor ${ }^{12}$-- (“¿Viste como hacen con la nariz cuando te ven?”- dice un pichi, pero no es por el olor, contesta otro, "Es la manera que tienen ellos de mirar a los argentinos").

V. Algo, sin embargo, sale a la luz. Aún sin articular palabras, el cuerpo que aguanta habla políticamente. Sin la épica del desafío ni la retórica de la resistencia heroica, el pichi aguanta una precariedad socialmente impuesta en nombre de un cuerpo (individual y colectivo) que está vivo y tiene derecho a la vida y a persistir, poniendo al descubierto no sólo lo que significa ser un cuerpo--a saber, una multiplicidad de relaciones con la comida, el clima, la luz, la movilidad y el reposo, la higiene, la proximidad de otros cuerpos, la asistencia de sistemas sociales--, sino también el fracaso y

\footnotetext{
${ }^{11}$ Las torturas y tormentos de los soldados en Malvinas fueron delitos de lesa humanidad, y por lo tanto no prescriben: a 36 años de la guerra, la fiscalía federal de Río Grande pidió la detención e indagatoria de 26 oficiales y suboficiales que actuaron en la guerra, acusados de 22 hechos de tortura ocurridos en el ámbito de uno de los regimientos que intervino en el conflicto. Dice el fiscal federal Marcelo Rapoport que "la aplicación generalizada de tormentos a la tropa resultó entonces la represión ilegal con la que las autoridades militares hicieron frente a los actos desesperados con que los conscriptosverdaderas víctimas de la hambruna-reaccionaron ante tremendas penurias". Ver "Las torturas a soldados en Malvinas", Página 12, 17 de mayo de 2018.

${ }^{12}$ La suciedad puesta en común, dice Barthes en Cómo vivir juntos, es signo de lo colectivo. ¿Pero cuándo un medio se torna sucio? Cuando el exceso de suciedad "determina una nueva conducta” (178).
} 
la injusticia de las instituciones de las que depende su supervivencia y que han fallado en su protección ${ }^{13}$.

No hay acción propiamente dicha afuera de la política si lo que entendemos por política es una lucha heroica o una acción verbal: la vida silenciosa del cuerpo, su necesidad de alimento, de abrigo, de techo, de calor, de descanso y protección del peligro, es un oscuro presupuesto de la acción que relega las vidas "infames" de los pichis al ámbito anónimo y rumoroso de un pueblo prepolítico ${ }^{14}$.

Pero en tanto desposeídos, ¿están realmente afuera del poder y la política? ¿Vamos a decir solamente que esas formas de vida ilegibles para el estado-nación no tienen realidad en términos políticos, sin interrogar, como lo hace la novela de Fogwill, los modos de establecer las fronteras sensibles entre lo que es palabra y lo que es grito, lo que es vida primaria y lo que se reconoce políticamente como humano, localizado más allá de la satisfacción de las necesidades denominadas "básicas"? ¿Vamos a quedarnos con ese escenario de vidas indigentes hundidas, devaluadas, descartables, identificando la naturaleza del hombre con la del poder que lo deja al desnudo, sin intentar hacer de la vulnerabilidad de la vida--que no es solo sufrir un daño sino la capacidad de todo cuerpo de afectar y ser afectado--una instancia de intervención y politización decisiva a la hora de pensar las luchas actuales contra la precariedad?

Ruptura de pacto, éxodo, defección de cuerpos que con sus movimientos, sus intensidades afectivas y su tendencia a formar parte de una multitud, obligan a repensar la política desde su base como inmanencia, hundida en una realidad material común a todos que es previa al presupuesto del estado y sus ficciones. "Una salida y no la libertad. Una línea de fuga viva y no un ataque”, decían Deleuze y Guattari (55) por la misma época que se escribe Los pichiciegos acerca de los deveniresanimales de los cuentos de Kafka, poblados de umbrales de intensidad donde la forma humana vive de deshacerse en la zona de contacto entre el lenguaje articulado y el grito y los ruidos del cuerpo orgánico. Devenir-animal no es volverse animal, sino trazar una línea que en su huir de las asignaciones y distribuciones fijas, traicionándolo todo, atraviesa la oposición entre la supervivencia animal "básica" y lo propiamente humano.

Portadores de una carga biológica insoportable, los pichiciegos trazan con su cuerpo el exterior de la subjetividad del soldado respecto de su lugar en un orden social y político ${ }^{15}$. A fuerza de perder la forma humana, los pichis abren un espacio adyacente donde la frontera que alguna vez sirvió para

${ }^{13}$ Ver Butler, Marcos de guerra (2010) y Lorey, State of Insecurity (2015). La vulnerabilidad es menos un principio existencial que una condición política distribuida en forma desigual a lo largo de una población en la que hay grupos marginados social y económicamente más vulnerables que otros y, en consecuencia más expuestos, al daño y la violencia de la precariedad infligida.

14 "La acción que caracteriza la resistencia se encuentra en los actos de habla o en las luchas heroicas, pero también podemos verla en esos gestos del cuerpo que indican rechazo, silencio, movimiento e inmovilidad deliberada", y que son, según Butler, "rasgos característicos de todos esos movimientos que ponen en marcha los principios democráticos de la igualdad y los principios económicos de la interdependencia en una misma acción” (Cuerpos aliados 218).

${ }^{15}$ Badiou localiza en la figura heroica del soldado anónimo el paradigma mismo de una humanidad capaz de existir más allá de sí misma, superando los límites de nuestras determinaciones vitales y sociales. Contra el fondo de ausencia actual de toda figura heroica, el heroísmo del soldado, dice Badiou, es "el infinito en obra en las acciones humanas..., la aparición luminosa, en una situación concreta, de algo que asume su humanidad más allá de los límites naturales del animal humano” (52). 
repartir cuerpos y significados adentro y afuera del orden nacional-estatal se disuelve. Pero no están afuera del estado, porque es precisamente la presencia del estado lo que desencadena esos vectores de desterritorialización que vacían la forma estatal del cuerpo. En este sentido, con sus cavidades y túneles en constante expansión, la pichicera constituye un desborde permanente del espacio estatal por el acontecimiento de resistencia de los cuerpos que, en su capacidad de aguantar y bastarse a sí mismos, ahuecan y desfondan la territorialidad nacional.

Los pichis no son mudos; hablan hasta por los codos desde que se despiertan. O al llegar, después de haber estado callado y esperando que se haga de noche para volver a la pichicera: "el que entra habla" (11). Pero antes incluso de pronunciar palabra alguna, en medio del retumbar de las explosiones, los cuerpos vibrátiles de los pichis "dicen", en su expresivo y desafiante estar allí, haciendo espacio, que son cuerpos y que no son desechables, que son iguales y que en condiciones de precariedad impuesta, resisten y aspiran a una vida más vivible, más digna y sustentable.

De hecho, la vida digna de ser vivida tiene que ser algo más que un mero sobrevivir. Porque en un principio, el alimento, el abrigo o el refugio que les falta a los pichis no es cualquier alimento, vestido o refugio; les falta, incluso si se trata de la guerra, alimento, vestimenta o refugio dignos, "acordes con lo que la comunidad considera deseable" (Scavino 56). Cuando enumeran sus fantasías, enuncian como sujetos de deseo, no de necesidad, que en la lógica de una justicia de los cuerpos, aspiran a una vida más vivible: tener sexo, dormir en una cama limpia, bañarse con agua caliente y jabón, estar en casa, comer bien - un asado o milanesas--, ver a los padres, especialmente a la madre. Todos, sin discusiones, extrañan el calor, todos quieren sentir el calor y acumular la energía del calor en el cuerpo hasta dejar de sentirlo porque el calor "es el mundo nomás" (123). Pero calentarse es otra cosa: “¿Por qué andan todos tan calientes por calentarse?”- pregunta Quique ya reintegrado a la vida civil ante el enigma del deseo del otro, encarnado por una mujer que "quería calentarme más para calentarse ella más, no sé por qué" (122). Igualmente, al Turco, uno de los pichis que mandan, "lo que más le calentaba" era cambiar cosas y mandar, lo mismo que al escritor, que le calienta saber (89).

En su desujetamiento y capacidad de devenir, los pichis exceden las coordenadas de lo viviente-esa geografía del hambre, del frío y del miedo que no basta para contener una serie abierta de deseos lanzados en estampida más allá de la mera supervivencia de la especie. Desbordantes de demandas insatisfechas que rebalsan los límites de la degradación y la precariedad impuesta, los pichis siempre piden más.

Nadie sabe lo que un pichi puede, ni siquiera ellos mismos. Parafraseando al Lamborghini de "El fiord", el pueblo hundido de los pichis, en contigüidad con el animal, perfora con su demanda insaciable de alimentación, abrigo y sexualidad el umbral entre lo meramente viviente y lo afectivo y deseante: como Sebas_las "bases" reducidas a la pura necesidad--los pichis quieren que les den de comer y de coger. Y en ese grito furioso de los cuerpos, que retumba entre las paredes de piedra de la pichicera, ya se escuchan las demandas democratizadoras de los jóvenes del menemismo de los años 
90, descreídos de la política electoral, abandonados a su suerte por el estado en el campo del terror económico, el desempleo crónico, la precarización laboral, la xenofobia y la violencia de género ${ }^{16}$.

VI. A la animalización de la vida por parte del poder, al mero estar vivo del que aguanta en la vulnerabilidad y precariedad de la guerra, los pichis oponen una vitalidad y un poder de creación que está en exceso respecto del orden biopolítico que los hace meramente vivir como víctimas lastimosas o como los espectros que rondan en las historias de aparecidos que intercambian los soldados. ${ }^{17}$

Así, al hecho de estar vivos para el orden biopolítico hegemónico, en el umbral compartido por hombres y animales, hay que superponerle el de ser vivos, los vivos de esta historia que comienza cuando un sargento interpela a Quique y a un par de soldados más en los términos de una pragmática, digamos, vitalista: “¿Uds. son boludos? ¡No! Ustedes no son boludos, ustedes son vivos. ¿Son vivos? -Chilló" $(17)^{18}$. (Y en ese chillido ya se anuncia la huida hacia lo informe de un cuerpo que va a ir deshaciéndose de su forma estatal hasta hacer surgir, en el borde exterior del lenguaje, la manada de pichiciegos.)

Bergson decía que lo viviente es esencialmente un ser que tiene problemas y los resuelve a cada instante (citado por Noys 64). Ser vivos, para los pichis, es en principio volver posible la vida, dándose reglas artificiales que potencien la praxis y los libren de ser los "boludos" de la historia. Si solo fueran víctimas de un estriamiento represivo, todo ese vitalismo involucrado en la creación de un espacio de intercambio comercial y almacenamiento de provisiones quedaría disuelto en un dejarse vivir languidecente a ras del cuerpo y sus necesidades insatisfechas. Por el contrario, lo que emerge del subsuelo de animalización y degradación de lo humano es un cálculo afirmativo de oportunidades de vida que, lidiando con lo incalculable de una situación, los saca del campo de la necesidad — si bien no de la pobreza. En este sentido, la picardía de los pichis resulta ser una política de desprecarización ambiguamente productiva; un arte de vivir improvisando hecho de tretas y ardides de supervivencia que en la tradición de la autogestión, Michel de Certeau le atribuye a quienes están obligados a hacerse cargo de condiciones que no eligieron (De Certeau 43).

De hecho, los que conocen la verdad acerca de los pichis y no creen que sean fantasmas ni muertos vivos son los ingleses y los argentinos que comercian con ellos y saben lo vivos que están y

\footnotetext{
${ }^{16}$ Lamborghini, "El fiord”, 22. Sigo a Gabriel Giorgi, que dice acerca de "El fiord” y la intersección entre el "animal” y el "pueblo" peronista: "Comer y coger: de eso estarán hechas, parece decir esta escritura, muchas luchas de la cultura y la política futuras. Allí ya están contenidas...las luchas que décadas después pondrán a piqueteros, travestis y prostitutas en el centro de las demandas democratizadoras reconfigurando los sentidos y los rostros de las luchas populares" (Giorgi 1812).

${ }^{17}$ En "El monstruo político. Vida desnuda y potencia", Antonio Negri (2007) opone su noción de "monstruo político" - el poder creativo y colectivo de la multitud, la masa fuera de los controles de la población que se resiste a las capturas del biopoder - al concepto de "vida desnuda" de Agamben, en el que lee una fantasmagoría ideológica que vacía los cuerpos y la vida de su potencia y capacidad afirmativa.

${ }^{18}$ Kohan lee la oposición entre "vivos" y "boludos" en término de devaluación del credo nacionalista: "El mundo de Los pichiciegos está dividido en dos: los vivos y los boludos... La adscripción a los fervores de la argentinidad lleva el sello inexorable de la boludez lisa y llana; en su contracara, los escépticos, los descreídos, son los que se avivan, son los vivos de esta historia". A un soldado, observa Kohan, le dicen "Galtieri” porque "es muy boludo y se creía que íbamos a ganar" (2014).
} 
lo vivos que son negociando, según una red de intercambios que, por abajo, abre caminos a formas colectivas de manejo de la precariedad impuesta "desde arriba". Abajo estaba, por ejemplo, el Turco, uno de los jefes del grupo, viviendo la guerra como una continuación del comercio por otros medios. ${ }^{19}$

Al Turco no le alcanzaba con enterrarse vivo a aguantar hasta el final de la guerra en el ocio improductivo. "Otro se hubiera contentado cuando acabaron de hacer el lugar" - cuenta Quique“Todos, menos él" (54), que durante esos días no va a dejar de inventar formas económicas que mejoren las condiciones de vida y las chances de salir vivos de la guerra. El miedo, que "suelta el instinto que cada uno lleva dentro", desencadena en el Turco el "instinto de amontonar las cosas y de cambiar" (89). Porque el Turco no era turco, sino un argentino hijo de libaneses al que la guerra, en buena lógica naturalista, le despierta "el árabe de adentro" (89)—que no es tanto un bagaje genético que recibe de la raza como una memoria familiar: el padre tenía almacén y una casa de repuestos y de ahí le venía "la maña para cambiar cosas" (55). Su mundo se despliega como un espacio de cálculos, un mundo de costos y beneficios, de variaciones de la oferta y la demanda, de iniciativas y perspectivas, de pequeños robos y artilugios: tretas del débil que de un modo táctico aprovecha la ocasión y saca ventajas de lo que puede.

Sobrevivir exige amplios recursos de ingenio y creatividad que al Turco no le faltan. Pragmático, el Turco tiene la movilidad y la capacidad de improvisación y adaptación que les permite aprovechar la ocasión y sacar ventaja de las oportunidades que se les van presentando. Pero lo suyo no es exclusivamente el interés egoísta del individuo que hace todo por utilidad. De hecho, el Turco, como el resto de los jefes del grupo, no estaban interesados en el dinero que podía juntarse en abundancia de los bolsillos de los muertos y de las casas vacías de las islas. "La plata no le interesaba" (53), dice la novela. Porque el Turco - volvemos a repetirlo--"se calentaba" con la idea de juntar cosas y de mandar (89), que estaba en su naturaleza como potencia que se activa con la guerra: el "instinto" mercantil de la raza. Su deseo es creativo y productivo más allá del rédito que pueda sacar de él, y en última instancia, no apunta tanto a enriquecerse y consumir como a la planificación del consumo y la satisfacción de las necesidades según un arte de gobernar que recuerda a lo que Foucault, en su genealogía del paradigma biopolítico, teorizó, por debajo del nivel de la soberanía, como gubernamentalización del estado ${ }^{20}$.

En efecto, mandar para el Turco es poner en acción una economía meticulosa de los hombres y de las cosas en su relación con el territorio y el clima, con los accidentes y los vaivenes de la guerra, con el hambre, el miedo y el frío, con la manera de actuar o de pensar de los pichis. "El pichi guarda,

\footnotetext{
${ }^{19}$ Fogwill: "El libro toma partido por la tesis clausewitziana de que la guerra es la continuación de la política por otros medios. A la que yo le agrego: que a su vez es una continuación del comercio, por otros medios" (entrevista de Matías Capelli, Los Inrockuptibles 103, mayo de 2006, citado por Kohan 2014).

${ }^{20}$ Entre 1976 y 1980, a lo largo de sus seminarios en el Collège de France Hay que defender la sociedad, Seguridad, territorio, población, El nacimiento de la biopolítica y Del gobierno de los vivos, Foucault descubre confundida con las micro prácticas de las sociedades disciplinarias una macroeconomía "biopolítica" del poder que no trabaja al nivel individual de los cuerpos sino en la imbricación hombres/cosas que constituye el espacio múltiple y heterogéneo de la población. Ver especialmente la clase del 1 de febrero de 1978 del curso 1977-1978 Seguridad, territorio, población, más conocida como "La gubernamentalidad" (2004).
} 
agranda, aguanta", repite a modo de consigna (54). En medio del dejar morir del ejército en el abandono y el desamparo, el Turco implementa todo tipo de Intervenciones para hacer vivir y pasar el invierno, según un acopio compulsivo de comida, carbón, kerosén, azúcar, yerba, cigarrillos, pilas, licor; pero también, para agrandar y mejorar la pichicera, hacerla más segura, más caliente y protegida. Quería, en definitiva, controlar las probabilidades de vida, seguir sus fluctuaciones--entendiendo la vida menos como una dimensión biológica que como un espacio de acontecimientos e imprevistos.

Guardar y mandar por el sólo placer de mandar constituye el núcleo de una fuerza y acción soberana que dice y hace la ley, sin discusión posible. Como en cualquier estado de excepción, no se necesita la ley para dictar la ley y el sentido. Nadie puede tener ideas mejores que los jefes, por ejemplo, porque "acá 'mejor' quiere decir lo que mandamos nosotros" (48)_le explican a un recién llegado que, no casualmente, es estudiantes de Derecho y ya habla como un abogado. Pero en la pichicera, la ley o, más precisamente, las reglas, no son un fin en sí mismo, sino un medio para preservar, maximizar y multiplicar eso que es menos una tropa de sujetos disciplinados que una colección de cuerpos organizados artificialmente para aumentar su poder de afección. El poder del Turco y el resto de los jefes no se despliega sobre el territorio ni sobre los cuerpos tomados uno por uno, sino sobre la imbricación de los pichis con las cosas en el espacio múltiple de la madriguera-un arte de gobernar el "entre" los cuerpos y de ejercer el poder bajo la forma de una economía que crece por medio de encuentros, cruces y conexiones con otros deseos en un espacio en red.

VII. "Córtense solos porque de esta no salimos vivos si no nos avivamos", les había advertido poco antes de morir el Sargento a los "magos", el trío de pichis con quienes comenzó todo. Y los mandó a cavar en el cerro lo que sería la pichicera, sin que el resto de la tropa se enterara, lejos de las trincheras (22).

La llamada a cortarse solos y avivarse para zafar de la guerra es de un individualismo paradójico. Por un lado, apela a las tendencias egoístas de sujetos que viven su ser social como identidad individual. Cada uno de los que se corta solo, por separado, trataría de sobrevivir en forma aislada, unido a los demás por el miedo, el odio al ejército y un mismo modo de ser: una banda de homo oeconomicus, arreglándoselas solos para satisfacer toda una serie de necesidades que se le presentan. Pero se trata de un individualismo que se encuentra en contradicción con el "nosotros" que retuerce la consigna, insinuando un principio de cooperación entre sujetos igualados por el hecho de estar vivos y unidos "desde abajo" por una precariedad compartida debido a la dependencia constitutivamente social de lo vivo (Lorey 16).

La vida y su potencial de trabajo no existe si los individuos actúan separadamente, dice Dardo Scavino a propósito de la desoladora moral de fin de siglo que Fogwill captó antes que nadie, y basta con que los colaboradores "se corten solos" para que el potencial de creación se disuelva por 
completo $^{21}$. El Turco lo sabe, en tanto gobierna aprovechando la superabundancia vital de los pichis, convertidos en población. Porque en las islas nadie sobrevive solo, ni se trata sólo de sobrevivir. Gracias al Sargento, el Turco entiende que en el frío de las islas el sólo hecho de vivir daba trabajo, y que para salir vivos de la guerra no bastaba con sobrevivir: como les había dicho el Sargento, había que avivarse y hacer hacer a los pichis, poniendo a trabajar esa multiplicidad lingüística, afectiva, intelectual, cooperativa que, en lo activo de su fuga, se constituye con los pichis.

El Turco no es el individuo que se cree autónomo e independiente, y se da cuenta que con robinsonadas, como decía Marx (41), no alcanza. Mi propia vida, parece decir el Turco, depende de una vida mucho más amplia que no es la mía, una organización social y económica que incluye la vulnerabilidad del cuerpo, la infraestructura que lo sostiene y las redes que estructuran su interdependencia. El Turco quería, por ejemplo, "agrandar la chimenea de un lado, romper la piedra grande y tapar todos los techos con fardos de lana para perder menos calor y para proteger mejor la pichicera de cualquier bombardeo" (55). Y para eso necesitaba incorporar mas pichis, producir más relaciones, más alianzas, más afectos-que es la capacidad de un cuerpo individual o colectivo de afectar o ser afectado por otros cuerpos, aumentando o disminuyendo su capacidad de actuar. "La gente sirve", razona el Turco. "Vienen más, traen más. ¡Hay que elegir que sirvan: traen cosas, tienen más conocidos en los batallones, pueden cambiar más cosas y ayudar!” (54).

Gobernar es poblar la madriguera de afectos, de pichis que cooperen entre sí. Porque sin colaboración, sin cooperación productiva, sin adoptar una forma social que vuelva posible la vida, las probabilidades de salir con vida se desvanecen. Náufragos de un estado-nación que se está hundiendo y los margina, el Turco intuye las pocas chances de sobrevivir en una isla si le ocurriera lo que a Robinson Crusoe. Sin embargo, aquí en las islas, todas las normas que presiden el trabajo de un Robinson se repiten, "sólo que con un carácter social y no individual" (Marx 43).

Gobernados en sus tendencias e intereses individuales, los pichis son ciegos a los que el Turco, con sus reglas y regulaciones, les hace hacer y producir a partir de la naturalidad de su deseo, según un juego de poder donde la población se manifiesta como fin e instrumento de un gobierno fundado en el cálculo de aquello que en la guerra escapa a los cálculos, a saber, los imponderables de la guerra.

Traducida siempre a un número, la vida es el objeto permanente de las previsiones del Turco, que se basa en el inventario de cosas que le provee Pipo, el pichi a cargo del almacén. Pipo anota y lleva la cuenta de todo lo que entra y sale del depósito. Incluso a la hora de ejercer el derecho soberano de hacer morir, arrojando a la intemperie a los pichis "dormidos" que, inutilizados por el miedo, se retiraban al rincón más oscuro de la pichicera a vivir de las sobras, se está jugando una racionalidad gubernamental que refuerza la vida de la población descartando a los cuerpos que, quebrados en su voluntad y sensibilidad, caían en lo más profundo del pozo negro de la especie. "Habría que tirar seis

\footnotetext{
${ }^{21}$ Scavino, a propósito de la cooperación y el trabajo vivo: “A este potencial que no está por sí mismo en ninguna de las partes tomadas una a una pero que aparece, de repente, cuando éstas comienzan a cooperar, se lo llamó a menudo 'vida'. Los médicos y anatomistas del Renacimiento cortaban los cuerpos en pedazos para ver dónde se escondía ese principio vital. Nunca, por supuesto, lo encontraron... Algo semejante ocurrió con quienes pretendieron explicar las sociedades a partir de los individuos aislados" (66-67)
} 
más-calculó el Turco" (91) en referencia a ellos, con la vida de la población en el horizonte de un cálculo que es eminentemente biopolítico.

Cualquier secuencia de la guerra (hombres, armas, pertrechos, provisiones ${ }^{22}$ ) es cuantificable económicamente y traducible a un número, como condición de un tipo de dominación política que funciona por extensión de las reglas del mercado sobre la totalidad de lo viviente. Esta suerte de neoliberalismo que inventan los pichis, surgido como dice Verónica Gago (2015), “desde abajo”, les permite captar la dimensión biopolítica del poder confundida con los mecanismos de superficie de la disciplina y de la soberanía, como los estaqueos y la tortura. Un oficial argentino que, ante el asombro de los pichis que lo ven, "se cocina" la mano en el hielo no está actuando como un loco, sino como un sujeto de una racionalidad biopolítica donde lo viviente del hombre se vuelve objeto de protección y seguridad social. "No te olvidés que es oficial, ellos en el colegio militar estudian eso: cálculo de riesgo, probabilidades"- les hace razonar el Turco: pierde una mano helada, se queda en el hospital, lo ascienden antes de pasarlo a retiro, "y va todos los meses con la mano que le quedó a cobrar el sueldo al banco... El Turco hizo las cuentas" (105). Igualmente, los aviones ingleses son materiales de guerra con una vida útil, lo cual se aplica también a sus pilotos. Así, "ver las cifras de lo que los británicos llaman la vida útil de las cosas asusta. Oír explicar cómo calculan ellos, pone piel de gallina" (129). De acuerdo a esta lógica, los británicos, socios comerciales de los pichis, son peores que los oficiales argentinos, "la hacen mejor, son más organizados, más hijos de puta", capaces incluso, en una pura lógica biopolítica, de "cambiarnos por cualquier cosa a los oficiales argentinos... y hacerte fusilar" (57).

VIII. De lo que no sabe el Turco es de la historias política o de la política a secas, que circula horizontalmente entre los pichis bajo la forma ansiosa, fragmentaria, confusa de una palabra democrática que en su vitalidad y su ansiedad por hacerse oír desordena el reparto ordenado y jerárquico de palabras y silencios. "Vos te callás. Vos sabés de mandar y de comprar y vender pero de esto no sabés una mierda" (39) - le exigen al Turco que se achica y se llama a silencio. Son los momentos en los que la palabra autoritaria de los jefes se interrumpe y retrocede frente a una palabra viva y abierta, capaz de hacerse oír por encima de las explosiones en el campo de batalla tanto como del silencio monolítico de la dictadura.

Cuando el alcohol y el miedo les suelta la lengua, los pichis se ponen a hablar todos al mismo tiempo, sin orden ni jerarquía, en un exceso no estadístico en ruptura con las cuentas armoniosas de cuerpos y significaciones del biopoder. “Por qué no hablan en orden?”, les pedía Pipo, el encargado de hacer el inventario.

Pero ese desorden tumultuoso, estigmatizado como algo bárbaro y apolítico por el liberalismo político, ¿no se denomina precisamente democracia? En esos momentos, en los que se ejerce la libertad

\footnotetext{
${ }^{22}$ Hasta los vuelos de la muerte de la dictadura se contabilizan económicamente del lado de las pérdidas: "Calculá: cien tipos por avión podrás tirar: son cien viajes. ¡Un cagadero de guita!” (40).
} 
de reunión y de expresión, la democracia se está poniendo en acto. Porque además de refugio y depósito de provisiones, la pichicera se vuelve un "almacén de opiniones" (41) repleto de pequeñas historias y verdades fragmentarias que surgen por los poros de una comunidad de individuos libres e iguales que descubren en la oscuridad de la pichicera una potencia de reunión y significación inédita. Claro, no estamos hablando de una república en miniatura - el bello animal constituido como armonía de partes en una totalidad orgánica. Tratándose de Fogwill y su política de la ficción, la democracia "literaria" no es tanto una cuestión de votos y de derechos como esa invención de palabras que poco después teoriza Rancière, por las cuales "los que no cuentan se hacen contar y desordenan así la partición ordenada de la palabra y del mutismo" (Politique de la littérature 51).

Sin exactitud, con una sobrecarga de imprecisiones, los pichis hablan del número de víctimas por la represión, de los vuelos de la muerte, del apoyo popular que tenía la guerrilla, de si Santucho era o no peronista, del "vivo" de Firmenich que "se rajó" (43) a Chile después de la fuga de presos del penal de Rawson, de dos monjas francesas "aparecidas" en plena noche, del retorno de la democracia. La cuenta errónea de la democracia consiste en poner a circular seres en exceso en un relato colectivo hecho con cosas oídas a medias, historias de resistencia, ficciones anónimas, hechos alterados o deformados cuya verdad, fragmentaria y polémica, hay que reconstruir en el cruce de versiones y opiniones. ${ }^{23}$ Hablar es entrar en una relación dialógica con la palabra ajena que implica apropiación y asimilación selectiva no solo de significaciones, sino de expresiones, entonaciones y voces. En este sentido, en sus bifurcaciones y sus giros, en su potencia de variación y de invención lingüística, la conversación entre los pichis representa un medio viviente de producción de enunciados, un espacio político donde se elaboran los deseos, las creencias y valores que intervienen en el proceso de constitución de una subjetividad que excede el mero "aguante" del soldado-ciudadano.

Así, la idea de población como puro dispositivo de sumisión, como mero sujeto biológico, queda puesta en cuestión cada vez que de la boca de un pichi se asoma, sobre el fondo negro de la piel sucia y escaldada del rostro, la punta de una de esas lenguas "húmeda, colorada y limpia" que pueblan la literatura de Fogwill, saliendo y entrando de los cuerpos para "gustar, explorar y significar" el mundo (Vivir afuera 8). Hablar se vuelve así un placer concreto que pone en juego una multitud de pasiones, valores y aspiraciones; un espacio de afirmación del cuerpo y los poderes que lo agitan, que no son más que la interiorización de los átomos de opinión que se propagan en ondas por un cuerpo social.

IX. La vida de los pichis, ese tejido vivo reconstruido a partir de percepciones y afectos, se prolonga hasta el testimonio de Quique y la palabra muda del escritor que tiene que hacer hablar a las piedras. En efecto, el accidente con la estufa de gas que terminó con la vida de los pichis (muerte por asfixia) vuelve a movilizar el umbral de indeterminación entre vida natural y vida política que atraviesa la novela. Quique cubre con barro y nieve la entrada de la pichicera, que pasado el invierno, con el

\footnotetext{
${ }^{23}$ Acerca de las dificultades y estrategias para reconstruir la verdad a partir de contrarrelatos alternativos a la ficción estatal, ver Piglia (23-30).
} 
descongelamiento y las filtraciones, comenzaría a derrumbarse y rellenarse de una materia mineral desplegándose según una temporalidad no humana: "la arcilla va a bajar, el salitre de las napas subterráneas va a trepar y los dos ingleses, los veintitrés pichis y todo lo que abajo estuvieron guardando, van a formar una sola cosa, una nueva piedra metida dentro de la piedra vieja del cerro" (135). Los cuerpos y las materias que los componen, los elementos atmosféricos e inorgánicos, se mezclan a una escala no humana en un suelo eminentemente biopolítico, cubierto de capas temporales de duraciones múltiples: el día y la noche, la historia, la memoria personal, la literatura, la degradación de los cuerpos, el nacimiento y la caída de un estado-nación, las modificaciones de la vida y de la muerte, las transformaciones de la materia, la chatarra de guerra, la erosión del suelo, el polvo.

Y una última visión, inexplicable: la de la naranja "fresca y pelada" (133) entre las papas y cebollas que caen rodando de una bolsa, un rasgo de abundancia vital que la aleja de la lógica de la petrificación que empieza apoderarse de la pichicera contaminada de gases venenosos. Esa naranja dulce y jugosa en medio de un cuadro fúnebre, fijada en la memoria afectiva del pichi sobreviviente, no debería pasar desapercibida, porque constituye, en medio de tanta muerte y tanto fango, un testimonio desafiante de vitalidad y de deseo: allí yace una vida colectiva, cifrada en un rasgo de superabundancia vital por la memoria de un pichi cualquiera con la capacidad de expresar una experiencia sensible común a todos. ¿Belleza de la resistencia de lo que Didi-Huberman llama "pueblos perdidos" (204), puesta por la vida allí donde menos se la esperaría?

"La única sorpresa, el única dispendio estético", observa acerca de la misteriosa naranja una fiel lectora de la novela, Beatriz Sarlo, a la que no se le puede escapar un detalle que en su mero estar ahí, sin función, sostiene lo que Barthes llamó efecto de realidad: "verosímil según la verosimilitud definida por Barthes", acota (Sarlo 452). Plus estético inútil en términos de significación, esa naranja salida de la nada, en su inmediatez material, no tendría para Sarlo ninguna otras razón para estar ahí que la de sobrecargar la novela de objetos y anclar a los pichis en lo real de los hechos tal como ocurrieron, sin capacidad de simbolizar ni reflexionar en "el origen de lo que les pasa" (Sarlo 453). Esa racionalidad que encadena causas y efectos a la manera de la ficción realista y de las ciencias sociales queda afuera del espacio fíccional de la novela, más allá del alcance de sus personajes, criaturas pasivas que viven día a día en el reino del detalle desencadenado y las preocupaciones prosaicas.

¿Y si no fuera así, como decía Quique cuando inscribía su testimonio en el campo del malentendido? La guerra de Los pichiciegos es una experiencia corporal que altera el mapa de lo sensible para hacer aparecer, por debajo de los grandes acontecimientos de la historia, de las hazañas y de los saberes especializados un régimen soterrado de sentido donde todos los seres, todas las cosas y todas las situaciones representan oportunidades de vida desconocidas. En ese mundo sobrecargado de materias y de sujetos que se aferran colectivamente a la vida, cualquier cosa es igualmente importante o insignificante, de manera que, como dice Rancière, el supuesto "efecto de realidad" que Barthes encuentra en Flaubert "es mucho más un efecto de igualdad" (El hilo perdido 25), en tanto 
desordena la jerarquía entre seres activos y pasivos o, tratándose de Fogwill, entre el saber totalizante de la teoría y el saber hacer de las pragmáticas vitalistas de los pichis.

Inseparables de la vulnerabilidad de los cuerpos, sus visiones son condensaciones de intensidades afectivas que penetran las palabras y las voluntades con las que se construyen los mundos vividos. Así, en su querer entenderlo todo y expresar lo virtual de una situación, los pichiciegos fueron capaces de ver en el futuro próximo no solo el retorno de la democracia, sino también, un poco más allá, la continuidad entre las políticas económicas de la dictadura y la democracia de mercado de la década del 90. Y también supieron, porque lo escucharon en el reverso de las interpelaciones que les dirigía el estado, que las promesas democráticas no se iban a cumplir, y que si por ellos fuera, como dijo uno de los pichis que no iba a votar a nadie, "ique se vayan todos a la puta madre que los remil parió!" (44). Sí, dijo "que se vayan todos", casi veinte años antes de los acontecimientos de fines de 2001, cuando una multitud salió a la calle a desafiar el estado de sitio y a protestar contra un nuevo ajuste del FMI, golpeando cacerolas y gritando la misma consigna ${ }^{24} \cdot i Y$ el mercado clandestino que inventan los pichis? ¿No es un presagio de las microeconomías informales, las estrategias comunitarias y el saber hacer con la crisis con que las clases populares se enfrentaron al terror económico y al vaciamiento del (modesto) estado de bienestar? "La argentinidad actual es pichiciega, vive del pequeño comercio con los amigos y los enemigos, medra, se oculta bajo tierra" - declara Fogwill en una entrevista de 2010, poco antes de morir. No vaya a ser que después digan que la literatura no avisó.

\section{Bibliografía}

BADIOU, Alain (2014): "La figura del soldado". Filosofía y política. Una relación enigmática. Trad. Horacio Pons. Barcelona, Amorrortu.

BARTHES, Roland (2003): Cómo vivir juntos. Simulaciones novelescas de algunos espacios cotidianos. Notas de cursos y seminarios en el Collège de France, 1976-1977. Trad. Patricia Wilson. Madrid, Siglo Veintiuno.

ButLER, Judith (2010): Marcos de guerra: las vidas lloradas. Trad. Bernardo Moreno Carrillo. Barcelona, Paidós.

(2017): Cuerpos aliados y lucha política. Hacia una teoría performativa de la asamblea. Trad. María José Viejo. Barcelona, Paidós.

CAlveIro, Pilar (2006): Poder y desaparición. Los campos de concentración en la Argentina. Buenos Aires, Colihue.

CAVAlletTI, Andrea (2010): Mitología de la seguridad: la ciudad biopolítica. Buenos Aires, Adriana Hidalgo.

De CerTeAu, Michel (1990): L'invention du quotidien. 1 Arts de faire. París, Gallimard.

\footnotetext{
${ }^{24}$ La observación es de Martín Kohan (2014), que dice: “Si algún presagio político contiene Los pichiciegos, justo allí donde la derrota de Malvinas iba a posibilitar la vuelta a la democracia, es el rechazo por el compadreo de la política eleccionaria".
} 
52 Tropelías. Revista de Teoría de la Literatura y Literatura Comparada, número extraordinario 4 (2018) Fermín A. Rodríguez

Deleuze, Gilles y Félix GuAtTARi (1983): Kafka. Por una literatura menor. Trad. Jorge Aguilar Mora. México, Era.

DiDi-Huberman, Georges (2014): Pueblos expuestos, pueblos figurantes. Trad. Horacio Pons. Buenos Aires, Manantial.

FogWILL, Rodolfo Enrique (1983): Los Pichy-cyegos. Visiones de una batalla subterránea. Buenos, Aires, De la Flor.

- (1998): Vivir afuera. Buenos Aires, Sudamericana. (2006): "Fogwill, en pose de combate". Entrevista de Martín Kohan. Revista Ñ, 25, marzo de 2006. Web: edant.clarin.com/suplementos/cultura/2006/03/25/u-01163931.htm

- (2010): "Fogwill y Los Pichiciegos: Visiones de una batalla subterránea". Entrevista de Augusto Munaro. Diario Los Andes, 21 de agosto de 2010. Web: www.losandes.com.ar/notas/2010/8/21/fogwill-pichiciegos-visiones-batalla-subterranea509326.asp

FouCAult, Michel (2004a): Seguridad, territorio y población. Cours au Collège de France 19771978. París, Gallimard.

(2004b): Naissance de la biopolitique. Cours au Collège de France. 1978-1979. París, Gallimard.

(2005): Historia de la sexualidad. Vol. I. La voluntad de saber. Trad. de Ulises Guiñazú. Madrid, Siglo XXI.

GAGO, Verónica (2014): La razón neoliberal. Economías barrocas y pragmática popular. Buenos Aires, Tinta Limón.

Gamerro, Carlos (2015): “Los Pichiciegos o la guerra de las ficciones”. Facundo o Martín Fierro. Los libros que inventaron la Argentina. Buenos Aires, Sudamericana.

GIORGI, Gabriel (2014): Formas comunes. Animalidad, cultura, biopolítica. Buenos Aires, Eterna Cadencia.

HARDT, Michel y Antonio NEGRI (2004); Multitud. Guerra y democracia en la era del Imperio, trad. Juan Antonio Bravo. Barcelona, Debate.

KoHAN, Martín (2014a): “A salvo de Malvinas”. Bazar americano. Año XI, N 48 (septiembre-octubre 2014). Web. Fecha de consulta: 7 de mayo de 2016.

(2014b): "La guerra de Malvinas: contrarrelatos". El país de la guerra. Buenos Aires, Eterna Cadencia.

LAMBORGHINI, Osvaldo (1988): “El fiord”. Novelas y cuentos. Buenos Aires, Del Serbal. (2018): "Las torturas a soldados en Malvinas", Página 12, 17 de mayo de 2018. Web: https://www.pagina12.com.ar/115293-las-torturas-a-soldados-en-malvinas

LOREY, Isabell (2015): State of Insecurity. Government of the Precarious. Trad. Ailleen Derieg. Londres, Verso, 2015.

LUDMER, Josefina (2010): Aquí América latina: una especulación. Buenos Aires, Eterna Cadencia. 
MarX, Karl (2000): El Capital. Crítica de la economía política. Tomo I. Trad. Wenceslao Roces. México, Fondo de Cultura Económica.

NoYs, Benjamin (2012): The Persistence of the Negative. A Critique of Contemporary Continental Theory. Edinburgh, Edinburgh UP.

PIGLIA, Ricardo (2001): Tres propuestas para el próximo milenio (y cinco dificultades). México, FCE. (2016): Las tres vanguardias. Buenos Aires, Eterna Cadencia.

RANCIERE, Jacques (2004): La malaise de l'esthétique. París, Galilée.

— (2007): “Le malentendu littéraire”, en Politique de la littérrature. París, Galilée.

— (2015): El hilo perdido. Ensayos sobre la ficción moderna. Trad. María del Carmen Rodríguez. Barcelona, Manantial.

SARLO, Beatriz (1994): "No olvidar la guerra de Malvinas", en Escritos sobre literatura argentina. Madrid, Siglo Veintiuno, 2007.

SCAVINO, Dardo (1999): La era de la desolación. Ética y moral en la Argentina de fin de siglo. Buenos Aires, Manantial.

SPERANZA, Graciela (2012): “Invisibles. Malvinas 1982-2012”. ex libris. Revista del Departamento de Letras \#1, pp. 420-427.

VeZZETTI, Hugo (2002): Pasado y presente. Guerra, dictadura y sociedad argentina. Madrid, Siglo Veintiuno.

VIRNO, Paolo (2011): Ambivalencia de la multitud. Entre la innovación y la negatividad. Buenos Aires, Tinta Limón.

ZIZEK, Slavoj (2016): Problemas en el paraíso. Del fin de la historia al fin del capitalismo. Trad. Damià Alou. Barcelona, Anagrama. 